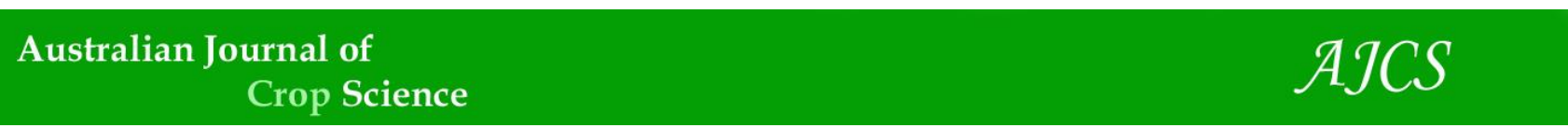

AJCS 15(04):510-517 (2021)

ISSN:1835-2707

doi: 10.21475/ajcs.21.15.04.p2779

\title{
Aspects in breeding maize for drought tolerance: Progress and modern breeding approaches
}

\author{
Aleck Kondwakwenda*, Julia Sibiya, Rebecca Zengeni, Cousin Musvosvi \\ University of KwaZulu-Natal, School of Agriculture, Earth and Environmental Sciences, Private Bag X01, \\ Scottsville 3209, Pietermaritzburg, South Africa
}

*Corresponding author: alekondwa@gmail.com; ; orcid.org/0000-0001-6786-3175

\begin{abstract}
Breeding for drought tolerance in plants is challenging because it is controlled by multiple genes. Grain yield, the trait of primary interest in maize, is characterized by low heritability, high genotype by environment interaction, and low variation under drought conditions, which further complicates selection. To circumvent these challenges, secondary traits that are highly correlated with grain yield are indirectly selected under drought conditions. Although considerable success in terms of yield gains under drought stress has been reported in both temperate and tropical maize breeding programmes, climate change exacerbated droughts coupled with high population growth necessitates continuous improvement of maize varieties. Understanding the genetics of associated secondary traits is essential in elucidating drought tolerance. The identification of quantitative trait loci (QTL) and candidate genes conferring drought tolerance and the subsequent development of relevant molecular markers ushered in the era of molecular assisted breeding. There is empirical evidence that marker-assisted selection and genomic selection have great potential to increase the yield gains while comprehensive and accurate phenotyping using secondary traits remains the pillar of drought tolerance breeding.
\end{abstract}

Keywords: Genetics, marker, morpho-physiological, phenotyping, selection.

Introduction

Maize (Zea mays L., $2 \mathrm{n}=2 \mathrm{x}=20$ ) is one of the important crops in the world, particularly in Africa, where it is a common staple crop. However, climate change exacerbated recurrent and episodic droughts are threatening maize productivity and agriculture worldwide. This puts food security at risk, especially in sub-Saharan Africa (SSA), where maize is mostly grown by poorly resourced subsistence farmers under dryland conditions (Cairns et al., 2012).

Genetic improvement of maize for drought tolerance through breeding provides a sustainable means of cushioning maize farmers from drought (Blum, 2011). It can reduce maize grain yield loss due to drought by $20-25 \%$ (Edmeades, 2013). However, drought tolerance is a complex trait that is controlled by many genes, each with minor effects on the ultimate performance of the cultivar. Grain yield, which is the primary trait of interest has low variation and heritability under drought conditions (Bänziger et al., 2004). Drought tolerance is also greatly affected by genotype and environment interaction. These aspects complicate selection for drought tolerance.

To remedy the challenges of selecting for grain yield under drought conditions, breeders indirectly select for secondary traits (Edmeades, 2013). Secondary traits constitute morphological, physiological, and biochemical mechanisms of responding to water stress. Many phenotypic and molecular-based methods of phenotyping maize for drought tolerance have been developed and applied in many drought tolerance breeding studies (Zia et al., 2013; Reynolds and Langridge, 2016; Kondwakwenda et al., 2019). Phenotypic methods range from the conventional low throughput manual-based to sophisticated high-throughput remote sensing-based methods (Bänziger et al., 2004; Makanza et al., 2018). Molecular methods include the use of candidate genes (CGs) and quantitative trait loci (QTL) analysis (Nikolić et al., 2012; $X u$ et al., 2014). Biochemical based phenotyping methods have not been adequately explored for large scale drought tolerance phenotyping in maize despite wide application in other crops (Flexas et al., 2004).

Despite all these challenges, drought tolerance breeding is quite an achievable task as evidenced by many droughttolerant maize cultivars released and considerably high genetic gains reported under drought stress in both tropical and temperate environments (Abdulmalik et al., 2017; Masuka et al., 2017a; Araus et al., 2018). However, empirical evidence has shown that the rates of genetic gain and cultivar turnover are inferior to what can be achieved by molecular assisted approaches (Beyene et al., 2019; Vivek et al., 2017). Overall, great strides have been made in breeding for drought tolerance maize in terms of genetic gains and application of molecular assisted breeding approaches, but the information is often reported in a disjointed manner. Therefore, this review seeks to (i) consolidate and discuss some of the key morpho-physiological and biochemical traits that are applicable for drought tolerance breeding in maize (ii) highlight some of the modern breeding strategies 
appropriate to drought tolerance improvement in maize and (iii) compile some of the latest yield genetic gains reported in maize breeding for drought tolerance under drought stress conditions focusing on tropical and subtropical SSA.

\section{Effects of drought on maize plant}

Drought disturbs the water status of the soil, plant, and atmosphere continuum (SPAC), disrupting the physiological, morphological, and biochemical processes of crops at a cell, tissue and whole plant levels. In severe cases, drought stress can trigger remobilisation of stem reserves, causing xylem embolism and cavitation, which in turn leads to premature and excessive stem and root lodging (Cochard, 2002). Drought can affect maize plants at any stage of growth. At seedling stages, drought affects plant establishment while at the reproductive stage it can cause poor fertilization and grain filling. Different genotypes react to drought stress in different manners and intensities, which allows breeders to make selections.

\section{Ideal secondary traits in maize breeding for drought tolerance}

Given the poor heritability and lack of genetic yield variation under drought stress, morpho-physiological and biochemical traits can be selected during drought tolerance breeding (Edmeades, 2013). An ideal trait should be highly correlated to grain yield, have high genetic variation, highly heritable, easy and cheap to measure, and be stable during the data collection period. The following subsections discuss some of the key morpho-physiological and biochemical traits that can be used as proxies for grain yield when selecting maize for drought tolerance. Table 1 shows some of the secondary traits associated with drought tolerance and their respective level of heritability and correlation to grain yield.

\section{Anthesis-silking interval and number of ears per plant}

Anthesis-silking interval (ASI) and the number of ears per plant (EPP) are the most applicable and utilised traits in breeding maize for drought tolerance (Betrán et al., 2003; Badu-Apraku et al., 2012; Bolaños and Edmeades, 1996). Anthesis-silking interval is the difference between the number of days to silking and anthesis, while EPP is the number of ears with at least one fully developed grain divided by the number of harvested plants in a plot (Bänziger et al., 2004). Anthesis-silking interval determines the pollen-silk synchronisation which is a critical aspect in maize hybrid development (Bolaños and Edmeades, 1996). Unlike grain yield, the heritability and variation of ASI do not decrease under drought stress but remain stable or even increase in some occasions (Bolaños and Edmeades, 1996). Moderate to high correlation coefficient values of -0.6 and -0.9 between GY, and ASI and EPP, respectively, have been reported under drought conditions (Bolaños and Edmeades, 1996). Thus, genotypes with reduced or negative ASI and high EPP should be selected under drought conditions (Bänzinger et al., 2000). Indirect selection for GY via ASI and EPP has been the cornerstone of many successful drought tolerance breeding programs in both tropical and temperate environments (Bolaños and Edmeades, 1996; Magorogosho et al., 2003; Campos et al., 2004; Beyene et al., 2016). In their review Ribaut et al. (2009) ranked ASI and EPP as best drought tolerance associated traits with high heritability and correlation values with grain yield, requiring less time and cost for data collection.

\section{Stay green}

Stay green or delayed leaf senescence refers to reduced cell/tissue death under environmental stress factors such as drought. Loss of chlorophyll and progressive reduction in photosynthetic capacity are the typical symptoms of leaf senescence (Tao et al., 2000). It is a post-anthesis trait, which should be measured during the grain-filling period. At the whole plant level, senescence reduces the receptiveness of silk and the viability of pollen, which can then result in poor fertilisation (Bassetti and Westgate, 1993). It is genetically controlled and exhibits a considerably high positive correlation with grain yield under drought conditions in maize (Bänziger et al., 2004; Zheng et al., 2009). Therefore, genotypes that exhibit delayed senescence should be selected under drought stress conditions by visually scoring during the grain filling stage. However, caution should be taken when scoring for a stay-green trait as other factors such as soil fertility status, especially nitrogen content can have confounding effects on the staygreen trait (Borrell et al., 2001; Subedi and Ma, 2005). Delayed plant senescence has also been linked to stem and root lodging resistance (Belícuas et al., 2014).

\section{Stomatal conductance and leaf rolling}

Plants respond to drought stress by closing the stomata and rolling their leaves. Reduced stomatal conductance under drought stress reduces xylem embolism and cavitation, which then increases maize survival (Cochard, 2002). The rate of stomatal closure and level of leaf rolling during drought stress varies genetically among different maize genotypes, which makes room for selection. Drought tolerant genotypes exhibit lower stomatal conductance, which is associated with increased leaf temperature and reduced water loss (Khan et al., 2007; Araus et al., 2012). Heritability ranges of stomatal conductance in maize under drought conditions are not well established. The ability of a plant to adjust osmotically when drought stress sets in determines the level of leaf rolling in which plants with high osmotic adjustment exhibit less leaf rolling and vice versa for those that exhibit high leaf rolling. Thus, genotypes with reduced leaf rolling should be earmarked as droughttolerant candidates (Kadioglu and Terzi, 2007).

\section{Root characteristics}

The maize root system is made up of embryogenic and postembryonic roots (Hochholdinger, 2009). The embryonic root system consists of single primary and seminal roots that are formed during embryogenesis and are responsible for water and nutrient uptake during the seedling stage of a maize plant. Hochholdinger, (2009) reported genetic variation in seminal roots, an indication that they can be used for selection in maize breeding. The postembryonic root system is composed of shoot borne and lateral roots that are responsible for water and nutrient transmission during the post seedling stage of a plant (Wang et al., 1995). The life span of the embryogenic root system varies among maize of different genetic backgrounds, which can also be the basis of selecting genotypes for drought tolerance. In some genotypes, it becomes obsolete with the emergence of the postembryonic root systems, while with others, it can remain functional throughout the life cycle of a plant supporting the postembryogenic roots. However, there is a need to establish the correlation of these traits with grain yield to justify their application in drought tolerance breeding. In their study of rooting depth and water use 
efficiency, Hund et al. (2009) found out that deep root system coupled with high water use efficiency (WUE) can enhance drought tolerance in maize.

Despite the importance of root characteristics in breeding for maize drought tolerance, there is a scarcity of information about their heritability levels. One of the major limitations of using the root structure as a trait for selection had been the difficulty in measuring non-destructively.

Lately, root capacitance meters have been introduced to measure root parameters without uprooting the plants, but they are too expensive for most of the under-resourced maize breeding programs, especially in developing countries (Messmer et al., 2011).

\section{Abscisic acid and proline content}

Drought stress causes cell osmotic adjustments increasing stress signaling hormones and key enzymes under drought (Yang et al., 2010; Shakeel et al., 2011). Abscisic acid (ABA) and proline accumulation are some of the notable biomolecules that are associated with drought response in plants. Abscisic acid induces stomatal closure, growth reduction, and is responsible for maintaining root elongation at low water potential (Ober and Sharp, 1994; Jovanović et al., 2000). It is also involved in the transcription and translation of several ABA-responsive genes, which are involved in plant water stress management (Obata and Fernie, 2012). Proline is an amino acid that plays an osmoregulatory role in plants exposed to drought conditions. Both $\mathrm{ABA}$ and proline content have been shown to increase with an increase in drought stress in most plants, including maize (Kondwakwenda et al. 2019). Hong-Bo et al. (2006) reported correlations between proline content and soil water stress threshold in their wheat drought tolerance study. In another study with rice, Vajrabhaya et al. (2001) observed a significant accumulation of proline in the leaves. In another study, Zegaoui et al. (2017) reported significant variation in proline accumulation among cowpea genotypes under drought conditions. Given these findings, the accumulation of proline under stress is linked with stress tolerance in many plant species. Although several studies have been done on proline accumulation under drought stress in other plants, its suitability for large scale drought tolerance selection in maize is worth investigating. Thus, there is a need to establish its expected heritability range and correlation level with maize grain yield under drought. It is important to note that the ultimate criteria for selecting drought-tolerant candidate genotypes should not be based on a single trait but rather a set of ideal traits computed using tolerance indices (Bänzinger et al., 2000; Blum, 2011).

\section{Genetics of maize drought tolerance}

Understanding the genetics of morpho-physiological and biochemical traits is vital in elucidating drought tolerance. Drought is a complex quantitative trait; therefore, its genetics is reported in terms of quantitative trait loci (QTLs) and candidate genes (Tsonev et al., 2009; Xu et al., 2014; Zhao et al., 2018). Following the advent of QTL mapping tools such as linkage and association mapping, several QTLS encoding for some of the key drought tolerance related morpho-physiological traits have been identified in maize and other major crops such as maize, rice, and wheat. For instance, QTLs for maize grain yield and yield components, ASI, root structure, stay green, leaf ABA among others have been reported (Landi et al., 2007; Hund et al., 2011; Messmer et al., 2011; Almeida et al., 2014).
Despite tremendous strides in QTL studies for drought tolerance improvement in maize, there is still a great challenge of identifying major and stable QTLs. Most QTLS reported are minor QTLs accounting for less than $10 \%$ of the phenotypic variation (Sehgal and Yadav, 2009; Mir et al., 2012; Shikha et al., 2017). Also, QTLs identified using given populations and environments may not be detected using different genotypes and environments, making it difficult for breeders to use the QTL in developing different populations (Hao et al., 2010). Modern technologies such as nextgeneration sequencing (NGS) technologies have become instrumental in identifying candidate genes underlying drought tolerance QTLs in major crops like maize.

Candidate genes confer drought tolerance through specific processes like encoding for proteins that are involved in cell protection under drought stress and regulate other genes participating in drought response (Mir et al., 2012). Pyrroline-5-carboxylate synthetase (P5CS) is a typical example of such genes. It is responsible for the enhanced accumulation of proline, which in turn causes osmotolerance (Sun et al., 2016). NADP-malic (NADP-Me) is another gene, which is overexpressed to reduce stomatal conductance under drought stress (Cattivelli et al., 2008). Some other candidate genes are the DREBs which encode the dehydration-responsive-element-binding proteins, which are stress-induced transcription factors that trigger the expression of downstream stress-related genes that confer drought tolerance (Cattivelli et al., 2008; Sehgal and Yadav, 2009).

Knowledge of candidate genes encoding for drought tolerance is useful for understanding drought tolerance and can be utilised in developing drought-tolerant maize cultivars through marker assisted selection (MAS, Mir et al., 2012). Identification of candidate genes and their subsequent validation enables the application of genetic engineering techniques in drought tolerance improvement. This area is still in its infancy in most developing countries due to a lack of supportive policies. Many drought-tolerance candidate genes have been identified (Ribaut et al., 2009; Sehgal and Yadav, 2009; Hao et al., 2010).

\section{Morden breeding approaches for drought tolerance in maize}

The identification of major and stable quantitative trait loci (QTL) conferring drought tolerance and the subsequent development of relevant molecular markers ushered in the era of molecular assisted breeding (Cerrudo et al., 2018). Major advantages of molecular assisted over exclusive conventional approaches include reduced breeding cycles and less dependence on environmental conditions. This speeds up the variety development process and increases variety turnover. The following sections discuss some of the molecular breeding approaches that can be applied in drought tolerance breeding in maize and the reported successes.

\section{Marker-assisted backcrossing}

Marker-assisted backcrossing (MABC) for drought tolerance improvement involves the introgression of validated drought-tolerant major QTL by crossing a confirmed drought tolerant donor with a commercially adopted less or nondrought tolerant recipient inbred line for several generations 
Table 1. morpho-physiological traits that are key in maize drought tolerance breeding, their level of heritability, and their relationship with grain yield under drought stress.

\begin{tabular}{|c|c|c|c|c|}
\hline Trait & Heritability & $\begin{array}{l}\text { Correlation with grain } \\
\text { yield }\end{array}$ & Selection & References \\
\hline Anthesis silking interval & Medium-high & High & Short ASI & (Lu et al., 2011) \\
\hline Number of ears per plant & High & High & Many ears per plant & (Bänzinger et al., 2000; Ribaut et al., 2009) \\
\hline Plant height & Medium & Medium & Short plants & (Betrán et al., 2003) \\
\hline Stay green/ leaf senescence & Medium & Medium & Delayed leaf senescence & (Borrell et al., 2001) \\
\hline Leaf rolling & Medium to high & Medium to low & Unrolled leaves & (Bänzinger et al., 2000) \\
\hline Stomatal conductance & $\ldots \ldots \ldots$ & Medium to high & Lower stomatal conductance & (Cochard, 2002) \\
\hline Tassel size & Medium to high & Medium & Smaller tassel with fewer branches & (Ribaut et al., 2009) \\
\hline Root structure & ............ & High & Deep roots & (Hochholdinger, 2009; Hund et al., 2009) \\
\hline$\Delta^{18} \mathrm{O}$ & ............... & ................ & Higher $\Delta^{18} \mathrm{O}$ & (Cabrera Bosquet et al., 2009) \\
\hline
\end{tabular}

0.7 to \pm 0.9 (high), \pm 0.5 to \pm 0.7 (medium), \pm 0.3 to \pm 0.5 (low) and \pm 0.00 to \pm 0.3 (negligible) according to Mukaka (2012).

Table 2. Some of the latest yield genetic gains reported under drought stress conditions for tropical maize.

\begin{tabular}{lllll}
\hline Rate of yield increase & Cultivar & Targeted trait(s) & Environment & Reference \\
\hline $51 \mathrm{kgha}^{-1} \mathrm{yr}^{-1}$ & Hybrid & GY, ASI & Managed drought & (Beyene et al., 2016) \\
$118 \mathrm{kgha}^{-1} \mathrm{yr}^{-1}$ & Hybrid & GY, ASI, PH & Managed drought & (Bankole et al., 2017) \\
$163 \mathrm{kgha}^{-1} \mathrm{yr}^{-1}$ & Hybrid & GY, ASI, SEN & Managed drought & (Abdulmalik et al., 2017) \\
$32.5 \mathrm{kgha}^{-1} \mathrm{yr}^{-1}$ & Hybrid & GY, ASI, PH & Managed drought & (Masuka et al., 2017a) \\
$22.7 \mathrm{kgha}^{-1} \mathrm{yr}^{-1}$ & Hybrid & ASI, GY, PH & Random drought & (Masuka et al., 2017a) \\
$29.2 \mathrm{~kg} \mathrm{ha}^{-1} \mathrm{yr}^{-1}$ & OPV & GY, ASI, PH & Random drought & (Masuka et al., 2017b) \\
\hline
\end{tabular}

GY- grain yield, ASI - anthesis silking interval, $\mathrm{PH}$ - Plant height, SEN - Leaf senescence. 
accompanied by marker-assisted selection (MAS) at every generation. This approach is ideal in the case of major QTLS as the one reported by Landi et al. (2007) of a root-ABA1 QTL responsible for root $A B A$ production under drought stress, which resulted in high leaf $A B A$ accumulation in the recipient cultivar under drought stress condition. Ribaut and Ragot, (2007) improved the drought tolerance of inbred line (CML287) by introgressing five QTLs responsible for yield components and anthesis-silking intervals under drought stress conditions. One of CIMMYT's popular droughttolerant line CML247 was developed using MABC (Xu et al., 2009).

\section{Marker-assisted recurrent selection}

Marker-assisted recurrent selection (MARS) involves a series of intermating accompanied by MAS at every cycle (Tester and Langridge, 2010). Lately, this method has been applied in many maize drought tolerance breeding programmes (Beyene et al., 2016; Abdulmalik et al., 2017; Bankole et al., 2017). In comparison to MABC, MARS has the advantage of increasing the frequency of other favorable alleles in addition to the targeted alleles into the advanced population as both intermated parents are selected for favorable alleles. A typical example of this scenario was reported by Abdulmalik et al. (2017) when they improved a maize population for both drought tolerance and Striga hermonthica resistance after three recurrent cycles. In another study, Bankole et al. (2017) reported a genetic gain of $7 \%$ per cycle of MARS under drought conditions.

\section{Genomic selection}

Genomic selection (GS) is one of the most recent molecularbased selection methods that are suitable for complex quantitative traits such as drought tolerance. It is based on the prediction of the genomic estimated breeding values (GEBV) of the selection candidates that have genotypic data but lack phenotypic information. Prediction is made using models that are developed using phenotypic and genotypic data of breeding materials that referred to as the training population (Newell \& Jannink, 2014). Thus, GS differs from other MAS approaches because of its predictive function. To increase the accuracy and efficiency of GS, high-density markers distributed throughout the whole genome should be used. Hence, it is encouraged to use genotyping-bysequencing (GBS) to genotype the breeding materials. As the cost of genotyping falling GS is becoming more ideal as it reduces both the cost and time of phenotyping the selection candidates. One of the main advantages of GS over markerassisted selection when breeding for drought tolerance is that it encompasses both minor and major marker effects (Meuwissen et al., 2001; Prasanna et al., 2020). In this regard, GS accounts for more genetic variation for a given trait than marker-assisted selection.

The applicability of GS to breeding was first proved in cattle (Prasanna et al., 2020; VanRaden et al., 2009) and lately in crops (Asoro et al., 2011; Beyene et al., 2019; Lorenz et al., 2012). Genomic selection was found to be superior to MAS for selecting grain yield and physiological traits under drought stress conditions by Cerrudo et al. (2018). In a comparative study Beyene et al., 2019 found out GS and conventional phenotypic selected candidate genotypes with similar yield performance under drought and optimum condition by the cost of GS were lower.

\section{Drought tolerance breeding progress in the tropics}

A lot of financial resources have been channelled into tropical and sub-tropical maize drought tolerance improvement projects in both public and private sectors (Bänziger et al., 2004; Campos et al., 2004). This has seen several drought-tolerant maize lines and cultivars being developed and released worldwide in the form of openpollinated varieties (OPVs) and hybrids (Anami et al., 2009; Edmeades, 2013). In SSA, for example, major projects focusing on drought tolerance maize improvement were recently undertaken under the auspices of Drought Tolerant Maize (DTMA), Water use Efficient Maize for Africa (WEMA), and lately the Stress Tolerant Maize (STM).

Considerable success has been reported in terms of yield genetic gains under both drought stress and non-drought stress conditions through the improvement of one or more morpho-physiological traits using conventional, molecularassisted, and transgenic breeding methods (Table 2).

\section{Conclusion}

Considerable progress has been made in breeding maize for drought tolerance. However, there is no room for slowing down the efforts given the predicted increases in maize demand due to high population growth amidst increased drought frequency and intensity due to climate change. Marker-assisted breeding, genomics, and genetic engineering are proving to be useful tools in boosting maize genetic gains under drought conditions. Comprehensive phenotyping using secondary traits remains the cornerstone of successful drought tolerance breeding. Thus, there is a need for alternative low-cost high-throughput phenotyping technologies primarily for the poorly resourced breeding programmes in developing countries. Further studies should also focus on identifying new traits associated with drought tolerance in maize to increase the efficiency of phenotyping, especially those related to the metabolic processes.

\section{Acknowledgments}

The authors would like to thank the Alliance for Green revolution in Africa (AGRA) for funding the maize breeding programme at the University of KwaZulu-Natal (UKZN), The World Academy of Science (TWAS) and the National Research Foundation (NRF) of South Africa for funding living expenses of the first author during his studies.

\section{References}

Abdulmalik RO, Menkir A, Meseka SK, Unachukwu N, Ado SG, Olarewaju JD, Gedil M (2017) Genetic gains in grain yield of a maize population improved through markerassisted recurrent selection under stress and non-stress conditions in west Africa. Front Plant Sci. 8: 841.

Anami S, De Block M, Machuka J, Van Lijsebettens M (2009) Molecular improvement of tropical maize for drought stress tolerance in sub-Saharan Africa. Crit Rev Plant Sci. 28: 16-35.

Almeida GD, Nair S, Borém A, Cairns J, Trachsel S, Ribaut JM, Bänziger M, Prasanna Boddupalli M, Crossa J, Babu R (2014) Molecular mapping across three populations reveals a QTL hotspot region on chromosome 3 for secondary traits associated with drought tolerance in tropical maize. Mol Breeding. 34:701-715. 
Araus JL, Kefauver SC, Zaman-Allah M, Olsen MS, Cairns JE (2018) Translating high-throughput phenotyping into genetic gain. Trends in Plant Science. 23:451-466.

Araus JL, Serret MD, Edmeades G (2012) Phenotyping maize for adaptation to drought. Front Physiol. 3:305.

Asoro FG, Newell MA, Beavis WD, Scott MP, Jannink JL (2011) Accuracy and training population design for genomic selection on quantitative traits in elite North American oats. Plant Genome-us. 4:132-144.

Badu-Apraku B, Akinwale R, Franco J, Oyekunle M (2012) Assessment of reliability of secondary traits in selecting for improved grain yield in drought and low-nitrogen environments. Crop Sci. 52:2050-2062.

Bankole F, Menkir A, Olaoye G, Crossa J, Hearne S, Unachukwu N, Gedil M (2017) Genetic gains in yield and yield-related traits under drought stress and favorable environments in a maize population improved using marker-assisted recurrent selection. Front Plant Sci. 8:808.

Banziger M, Setimela P, Hodson D, Vivek B (2004) Breeding for improved drought tolerance in maize adapted to southern Africa. Resilient crops for water-limited environments: Proceedings of a Workshop. Paper presented at the resilient crops for water-limited environments: proceedings of a workshop in Mexico. CIMMYT.

Bänzinger M, Edmeades GO, Beck D, Bellon M (2000) Breeding for Drought and Nitrogen Stress Tolerance in Maize: From Theory to Practice. Mexico DF CIMMYT.

Bassetti P, Westgate ME (1993) Water Deficit Affects Receptivity of Maize Silks. Crop Sci. 33:279-282.

Belícuas PR, Aguiar AM, Bento DAV, Câmara TMM, Souza Junior CLD (2014) Inheritance of the stay-green trait in tropical maize. Euphytica. 198:163-173.

Betrán FJ, Beck D, Bänziger M, Edmeades GO (2003) Secondary traits in parental inbreds and hybrids under stress and non-stress environments in tropical maize. Field Crop Res. 83:51-65.

Beyene Y, Semagn K, Crossa J, Mugo S, Atlin GN, Tarekegne A, Bänziger M (2016) Improving maize grain yield under drought stress and non-stress environments in subSaharan Africa using marker-assisted recurrent selection. Crop Sci. 56:344-353.

Beyene Y, Gowda M, Olsen M, Robbins KR, Pérez-Rodríguez P, Alvarado G, Crossa J (2019) Empirical comparison of tropical maize hybrids selected through genomic and phenotypic selections. Front Plant Sci.10:1502.

Blum A (2011) Phenotyping and selection. In Plant breeding for water-limited environments. Springer, New York, $p$ 153-216

Bolaños J, Edmeades GO (1996) The importance of the anthesis-silking interval in breeding for drought tolerance in tropical maize. Field Crop Res. 48:65-80.

Borrell A, Graeme H, Erik O, (2001) Stay-green: A consequence of the balance between supply and demand for nitrogen during grain filling? Ann Appl Biol: 138:91-95.

Cabrera Bosquet L, Sanchez C, and Araus J (2009) Oxygen isotope enrichment $\left(\Delta^{18} \mathrm{O}\right)$ reflects yield potential and drought resistance in maize. Plant Cell Environ. 32:14871499.

Cairns JE, Sonder K, Zaidi PH, Verhulst N, Mahuku G, Babu R, Prasanna BM (2012) Chapter one - Maize production in a changing climate: Impacts, adaptation and mitigation strategies. In Sparks DL (ed) Advances in agronomy. Academic Press. 114:1-58:
Campos H, Cooper M, Habben JE, Edmeades GO, Schussler JR (2004) Improving drought tolerance in maize: A view from industry. Field Crop Res. 90:19-34.

Cattivelli L, Rizza F, Badeck FW, Mazzucotelli E, Mastrangelo AM, Francia E, Stanca AM (2008) Drought tolerance improvement in crop plants: An integrated view from breeding to genomics. Field Crop Res. 105:1-14.

Cerrudo D, Cao S, Yuan Y, Martinez C, Suarez EA, Babu R, Trachsel S (2018) Genomic selection outperforms markerassisted selection for grain yield and physiological traits in maize doubled haploid population across water treatments. Front Plant Sci. 9:366.

Cochard H (2002) Xylem embolism and drought-induced stomatal closure in maize. Planta. 215:466-471.

Edmeades GO (2013) Progress in achieving and delivering drought tolerance in maize - An update. ISAAA: Ithaca. NY. 130.

Flexas J, Bota J, Loreto F, Cornic G, Sharkey TD (2004) Diffusive and metabolic limitations to photosynthesis under drought and salinity in $C_{3}$ plants. Plant Biol. 6:269279.

Hao Z, Li X, Liu X, Xie C, Li M, Zhang D, Zhang S (2010) Metaanalysis of constitutive and adaptive QTL for drought tolerance in maize. Euphytica. 174:165-177.

Hochholdinger F (2009) The maize root system: Morphology, anatomy, and genetics. In J. Bennetzen and S.Hake (eds) Handbook of maize: Its Biology. New York: Springer.

Hong-Bo S, Xiao-Yan C, Li-Ye C, Xi-Ning Z, Gang W, Yong-Bing $Y$, Zan-Min $H$ (2006) Investigation on the relationship of proline with wheat anti-drought under soil water deficits. Colloids and Surfaces B: Biointerfaces. 53:113-119.

Hund A, Ruta N, Liedgens M (2009) Rooting depth and water use efficiency of tropical maize inbred lines differing in drought tolerance. Plant Soil. 318:311-325.

Hund A, Reimer R, and Messmer R (2011) A consensus map of QTLs controlling the root length of maize. Plant Soil. 344:143-158.

Jovanović L, Stikić R, Hartung W (2000) Effect of osmotic stress on abscisic acid efflux and compartmentation in the roots of two maize lines differing in drought susceptibility. Biol plantarum. 43:407-411.

Kadioglu A, Terzi R (2007) A dehydration avoidance mechanism: Leaf rolling. Bot Rev. 73:290-302.

Khan HUR, Link W, Hocking TJ, Stoddard FL (2007) Evaluation of physiological traits for improving drought tolerance in faba bean (Vicia faba L.). Plant Soil. 292:205-217.

Kondwakwenda A, Sibiya J, Zengeni R, Musvosvi C, Tesfay S (2019) Screening of provitamin-A maize inbred lines for drought tolerance: Beta-carotene content and secondary traits. Agronomy. 9:692.

Landi P, Sanguineti MC, Liu C, Li Y, Wang TY, Giuliani S, Tuberosa R (2007) Root-ABA1 QTL affects root lodging, grain yield, and other agronomic traits in maize grown under well-watered and water-stressed conditions. J Exp Bot. 58:319-326.

Lorenz AJ, Smith KP, Jannink JL (2012) Potential and optimization of genomic selection for fusarium head blight resistance in six-row barley. Crop Sci. 52:609-1621.

Lu Y, Hao Z, Xie C, Crossa J, Araus JL, Gao S, Xu Y (2011) Large-scale screening for maize drought resistance using multiple selection criteria evaluated under water-stressed and well-watered environments. Field Crops Res. 124: 3745. 
Magorogosho Pixley KV, Tongooona P (2003) Selection for drought tolerance in two tropical maize populations. Afr Crop Sci. j. 11: 151-161.

Makanza R, Zaman-Allah M, Cairns J, Magorokosho C, Tarekegne A, Olsen M, Prasanna B (2018) High-Throughput phenotyping of canopy cover and senescence in maize field trials using aerial digital canopy imaging. Remote sens-basel. 10: 330.

Masuka B, Atlin G, Olsen M, Magorokosho C, Labuschagne M, Crossa J, Cairns JE (2017a) Gains in maize genetic improvement in eastern and southern Africa. I. CIMMYT hybrid breeding pipeline. Crop Sci. 57:168-179.

Masuka B, Magorokosho C, Olsen M, Atlin GN, Bänziger M, Pixley KV, Cairns JE (2017b) Gains in maize genetic improvement in eastern and southern Africa: II. CIMMYT open-pollinated variety breeding pipeline. Crop Sci. 57:180-191.

Messmer R, Fracheboud $Y$, Bänziger M, Stamp P, Ribaut JM (2011) Drought stress and tropical maize: QTLs for leaf greenness, plant senescence, and root capacitance. Field Srops Res. 124:93-103.

Meuwissen THE, Hayes BJ, Goddard ME (2001) Prediction of total genetic value using

genome-wide dense marker maps. Genetics. 157:18191829.

Mir RR, Zaman-Allah M, Sreenivasulu N, Trethowan R, Varshney RK (2012) Integrated genomics, physiology and breeding approaches for improving drought tolerance in crops. Theor Appl Genet. 125: 625-645.

Mukaka MM (2012) Statistics corner: A guide to the appropriate use of correlation coefficient in medical research. Malawi Med J. 24: 69-71.

Newell MA, Jannink JL (2014) Genomic selection in plant breeding. In Crop Breeding.Springer.117-130.

Nikolić A, Ignjatović-Micić D, Dodig D, Anđelković V, LazićJančić V (2012) Identification of QTLs for yield and drought-related traits in maize: Assessment of their causal Relationships. Biotechnol Biotec Eq. 26:2952-2960.

Obata T, Fernie AR (2012) The use of metabolomics to dissect plant responses to abiotic stresses. Cell Mol Life Sci. 69:3225-3243.

Ober ES, Sharp R E (1994) Proline accumulation in maize (Zea mays L.) primary roots at low water potentials (I. Requirement for increased levels of abscisic acid). Plant Physiol. 105:981-987.

Prasanna B, Nair SK, Babu R, Gowda M, Zhang X, Xu Y, Zaman-Allah $M(2020)$ Increasing genetic gains in maize in stress-prone environments of the tropics. In: Kole C (eds) Genomic designing of climate-smart cereal crops. Springer. 97-132).

Reynolds M, Langridge P (2016) Physiological breeding. Curr opin plant biol. 31:162-171.

Ribaut JM, Betran J, Monneveux P, Setter T (2009) Drought tolerance in maize. In: Bennetzen JL, Hake SC (ed) Handbook of Maize: Its biology. Springer, New York.

Ribaut JM, Ragot M (2007) Marker-assisted selection to improve drought adaptation in maize: the backcross approach, perspectives, limitations, and alternatives. J Exp Bot. 58:351-360.

Robinson H, Comstock RE, Harvey P (1949) Estimates of heritability and the degree of dominance in corn. Agron J. 41:353-359.
Sehgal D, and Yadav R (2009) Molecular marker-based approaches for drought tolerance. In Jain SM and Brar DS (eds) Molecular techniques in crop improvement. Springer, Netherlands.

Shakeel AA, Xiao-yu X, Long-chang W, Muhammad FS (2011) Morphological, physiological and biochemical responses of plants to drought stress. Afr j Agric Res. 6:2026-2032.

Shikha M, Kanika A, Rao AR, Mallikarjuna MG, Gupta HS, Nepolean T (2017) Genomic selection for drought tolerance using genome-wide SNPs in maize. Front Plant Sci. 8:01-12.

Subedi KD, Ma BL (2005) Nitrogen uptake and partitioning in stay-green and leafy maize hybrids. Crop Sci. 45:740-747.

Sun C, Gao X, Chen X, Fu J, Zhang Y (2016) Metabolic and growth responses of maize to successive drought and rewatering cycles. Agr Water Manage. 172:62-73.

Tao YZ, Henzell RG, Jordan DR, Butler DG, Kelly AM, McIntyre $\mathrm{CL}$ (2000) Identification of genomic regions associated with stay green in sorghum by testing RILs in multiple environments. Theor Appl Genet. 100:1225-1232.

Tester M, Langridge P (2010) Breeding technologies to increase crop production in a changing world. Science. 327:818-822

Tsonev S, Todorovska E, Avramova V, Kolev S, Abu-Mhadi N, Christov NK (2009) Genomics assisted improvement of drought tolerance in maize: QTL approaches. Biotechnol Biotec Eq. 23:1410-1413.

Vajrabhaya M, Kumpun W, Chadchawan S (2001) The solute accumulation: The mechanism for drought tolerance in RD23 rice (Oryza sativa L.) lines. Sci Asia. 27:93-97.

VanRaden P, Van Tassell C, Wiggans G, Sonstegard T, Schnabel R, Taylor J, Schenkel F (2009) Invited review: Reliability of genomic predictions for North American holstein bulls. J Dairy Sci. 92:16-24.

Vivek B, Krishna GK, Vengadessan V, Babu R, Zaidi P, Kha LQ, Krothapalli K (2017) Use of genomic estimated breeding values results in rapid genetic gains for drought tolerance in maize. The Plant Genome. 10:1-8.

Wang XL, McCully ME, Canny MJ (1995) Branch roots of zea $\checkmark$ structural features that may influence water and nutrient transport. Bot Acta. 108:209-219.

Xu J, Yuan Y, Xu Y, Zhang G, Guo X, Wu F, Lu Y (2014) Identification of candidate genes for drought tolerance by whole-genome resequencing in maize. BMC plant biol.14:83

Xu Y, Skinner DJ, Wu H, Palacios-Rojas N, Araus JL, Yan J, Crouch JH (2009) Advances in maize genomics and their value for enhancing genetic gains from breeding. International journal of plant genomics.30. International journal of plant genomics. 2009:30.

Yang S, Vanderbeld B, Wan J, Huang Y (2010) Narrowing down the targets: towards successful genetic engineering of drought-tolerant crops. Mol Plant. 3:469-490.

Zegaoui Z, Planchais S, Cabassa C, Djebbar R, Belbachir OA, Carol P (2017) Variation in relative water content, proline accumulation and stress gene expression in two cowpea landraces under drought. J Plant Physiol. 218:26-34.

Zhao, X., Peng, Y., Zhang, J., Fang, P., \& Wu, B. (2018). Identification of QTLs and meta-QTLs for seven agronomic traits in multiple maize populations under well-watered and water-stressed conditions. Crop Sci. 58:507-520. 
Zheng $\mathrm{HJ}$, Wu AZ, Zheng CC, Wang YF, Cai R, Shen XF, Dong ST (2009) QTL mapping of maize (Zea mays) stay-green traits and their relationship to yield. Plant Breeding. 128:54-62.
Zia S, Romano G, Spreer W, Sanchez C, Cairns J, Araus JL, Müller J (2013) Infrared thermal imaging as a rapid tool for identifying water-stress tolerant maize genotypes of different phenology. J Agron Crop Sci. 199:75-84. 